\title{
Investigation of the Effect of Different Flow-Through Cell Designs on the Release of Diclofenac Sodium SR Tablets
}

\author{
Laila H. Emara ${ }^{1}$, Nesrin F. Taha ${ }^{1,3}$, and Nadia M. Mursi ${ }^{2}$ \\ 'Industrial Pharmacy Laboratory, Division of Pharmaceutical Industries, National Research \\ Centre, El-Tahrir Street, Dokki, Giza 12622, Egypt \\ 2Department of Pharmaceutics, Faculty of Pharmacy, Cairo University, Egypt
}

\begin{abstract}
This study was proposed to evaluate the effect of different cell designs and hydrodynamic conditions of the flow-through cell (FTC), USP dissolution Apparatus 4, on the release rate of a sustained-release product. Sustained-release (SR) diclofenac sodium (DS), $100 \mathrm{mg} /$ tablet, was selected for this study. Different cell sizes and types, the flow rate of dissolution medium, and the tablet position within the FTC were considered. Results revealed that some of these variables affect the release rate of DS. It was obvious that the turbulent flow of the dissolution medium resulted in a higher DS release rate compared with the laminar flow. In addition, the results show that the drug release rate decreased when the tablet was buried in the glass beads compared with the unburied tablet. On the other hand, variables such as cell size (12-mm and $22.6-\mathrm{mm}$ diameter), flow rates ( 8 and $16 \mathrm{~mL} / \mathrm{min})$, and presence of a tablet holder had a negligible role in drug release rate.
\end{abstract}

\section{INTRODUCTION}

A vailable evidence has shown that dissolution testing provides the means to evaluate critical parameters, such as bioavailability, and provides information necessary to the formulator in developing more efficacious and therapeutically optimal dosage forms. The FDA has stated that bioavailability testing utilizing human volunteers should be minimized by the development and implementation of in vitro dissolution standards that reflect in vivo drug performance (1). In general, dissolution testing can be used to (1) detect the influence of critical formulation and manufacturing variables during product formulation and development; (2) assist in selection of the best formulation; (3) monitor changes during stability studies; (4) establish final dissolution specifications for the pharmaceutical dosage form; (5) develop in vitro-in vivo correlation, (6) serve as a quality control tool; and (7) establish the similarity of pharmaceutical dosage forms, for which composition, manufacturing process, or equipment may have changed (2).

The value of dissolution as a quality control tool for predicting in vivo performance of a drug product is significantly enhanced if an in vitro-in vivo relationship (correlation or association) is established. The in vitro test serves as a tool to distinguish between acceptable and unacceptable batches. For the production of generic products, dissolution studies are carried out during product development and for quality control. After the development of a generic product, a pivotal bioequivalence study should be carried out according to reference

${ }^{3}$ Corresponding author. guidelines (FDA, EMEA, and WHO). The biobatch dissolution study data will be the measure of product performance. Acceptable products are bioequivalent, whereas unacceptable products might be bioinequivalent. To achieve an in vitro-in vivo correlation, at least three batches that differ in both in vivo and in vitro performance should be available. If the batches show differences in bioavailability, then the in vitro test conditions can be modified to achieve an in vitro-in vivo correlation. If the bioavailability of the batches is the same and the in vitro performance is different, it may be possible to modify test conditions to achieve the same dissolution profiles for the batches studied in vivo. Very often, the in vitro dissolution test is more sensitive and discriminating than the in vivo test. Any change in the quality of the active or inactive ingredients may affect the bioavailability of the product; therefore, a more discriminative dissolution method is preferred. From a quality assurance point of view, a more discriminative dissolution method is preferred, because the test will indicate possible changes in the quality of the product before the in vivo performance is affected.

The importance of in vitro dissolution testing has been recognized by pharmaceutical scientists since the early 1930s (3). The regulatory test was made official in 1970 with the adoption of USP Apparatus 1 as the official apparatus, followed later by the introduction of Apparatus 2. Yet there have been obvious and insurmountable limitations to the official dissolution testing apparatus (i.e., the rotating paddle and basket) concerning maintenance of sink conditions for drugs that saturate rapidly in large volumes of media. In addition, the model character of the test requires, in special cases, a change of $\mathrm{pH}$ (i.e., a change of fluid), which presents problems with the 
basket methods. One of the best known limitations of the official dissolution testing apparatus is associated with dissolution testing of suppositories $(4,5)$, as well as conventional hard-gelatin capsules due to clogging $(6,7)$. Because the capsule sometimes sticks to the mesh or the rotating paddle, the release of the drug might not be uniform (not reproducible). Since the introduction of USP Apparatus 2, there had been numerous reports of unexplained variability in products that are otherwise highly uniform (8-11).

The flow-through cell (FTC), shown in Figure 1, has been used successfully to study the dissolution of conventional and controlled-release tablets and hard and soft gelatin capsules (12). The reproducibility and ruggedness of this dissolution technique has been established in collaborative experiments at several independent laboratories using USP calibrator tablets $(13,14)$. The results from these studies demonstrate that FTC is a useful tool to study the dissolution of oral solid dosage forms. The FTC dissolution apparatus effectively solves the problem of nonsink conditions by supplying an unlimited quantity of fresh dissolution medium with a convenient change of $\mathrm{pH}$. The FTC has been officially accepted as USP Apparatus 4. This method offers distinct advantages compared with the USP

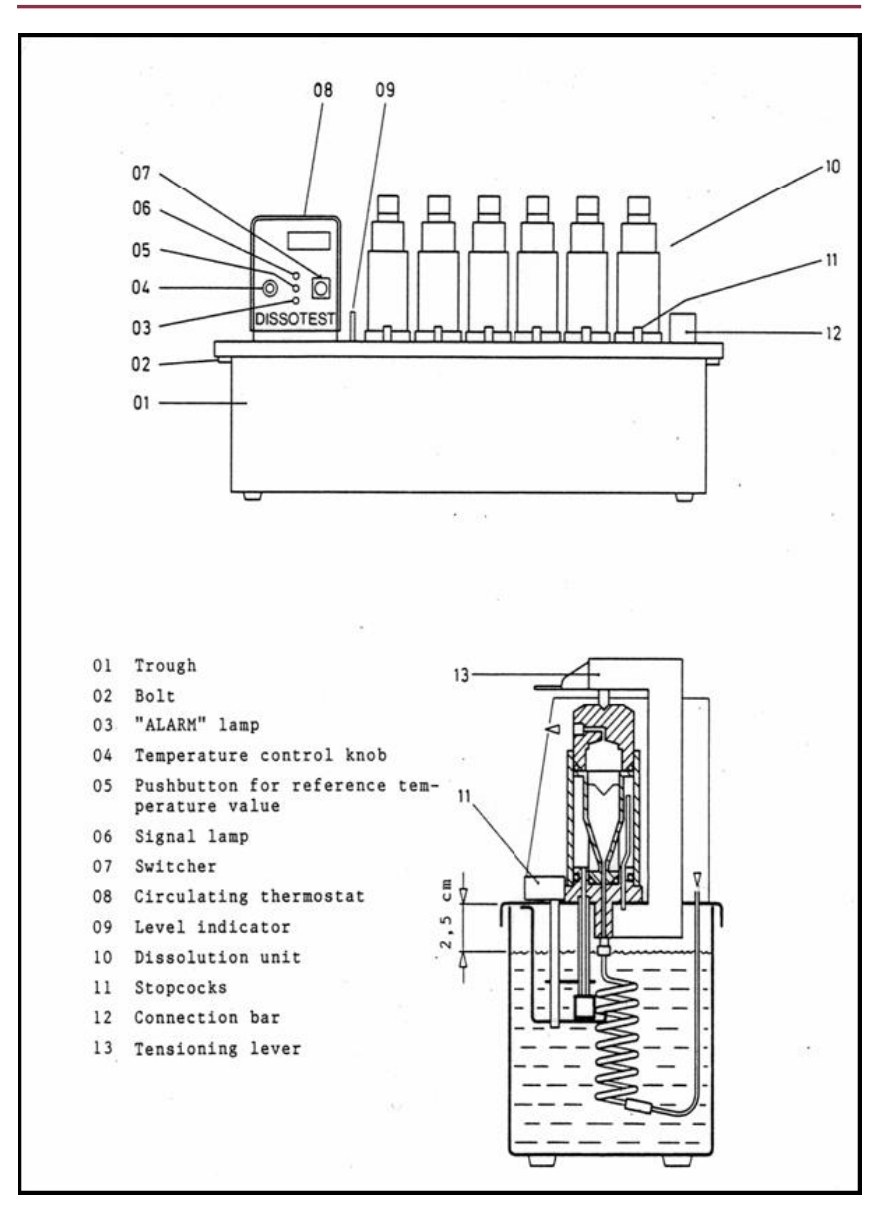

Figure 1. Flow-through dissolution apparatus FTC (USP Apparatus 4). paddle and basket methods, especially for drugs with poor solubility and wettability. FTC systems offer other distinct advantages including (1) a built-in filtration system, (2) use as either an open or closed system, (3) a high degree of automation, and (4) ideal hydrodynamic conditions for mild agitation, homogeneity, and definable flow (3). Few studies $(12,15-20)$ have discussed the optimization of the different FTC parameters that affect the release of drugs, such as flow rate, the type of flow (laminar or turbulent), cell size, gradient change of $\mathrm{pH}$ of the dissolution medium, closed and open system of the FTC, and the position of the dosage form in the dissolution cell. The objective of this study was to investigate different variables and hydrodynamic conditions in the FTC that might affect the release rate of a partially soluble DS (solubility $>9 \mathrm{mg} / \mathrm{mL}$ in deionized water at $\mathrm{pH} 5.2$ and $25^{\circ} \mathrm{C}$ ) from sustained-release tablets (21).

\section{MATERIALS AND METHODS Materials}

All products used in this study contained $100 \mathrm{mg}$ of DS. Reference product R1 was Voltaren film-coated tablets, obtained from Novartis Pharma, S. A. E., Cairo, Egypt, under license from Novartis Pharma AG, Basel, Switzerland (batch number 227). Reference Product R2 was Voltaren Retard film-coated tablets, Novartis Pharma AG, Basel, Switzerland (batch number SO064). Generic product G1 was Olfen SR hard gelatin capsules, MUP, Egypt, under license from Mepha, Basel, Switzerland (batch number PT1070); G2 was Declophen SR hard gelatin capsules, Pharco Pharmaceutical, Alexandria (batch number 136); and G3 was Rheumafen SR hard gelatin capsules, Glaxo Wellcome, Egypt (batch number 032803A). Sodium hydroxide pellets and potassium dihydrogen orthophosphate were purchased from Laboratory Rasayan, India. Distilled water was Milli RO plus 10, sourced from Millipore, USA.

\section{Methods}

Analysis of DS

A standard curve ranging from 0.2 to $20 \mu \mathrm{g} / \mathrm{mL}$ in phosphate buffer ( $\mathrm{pH}$ 6.8) was constructed. A stock solution was prepared by dissolving $10 \mathrm{mg}$ of DS powder in $50 \mathrm{~mL}$ methanol to yield a concentration of $200 \mu \mathrm{g} / \mathrm{mL}$. This solution was serially diluted with $\mathrm{pH} 6.8$ phosphate buffer to yield the desired concentration range. The absorbance of the prepared solutions was measured spectrophotometrically (DU-650 UV-vis spectrophotometer, Beckman, USA) at $\lambda_{\max }$ of $275 \mathrm{~nm}$ against a blank of pH 6.8 phosphate buffer. The absorbance was plotted against the concentration, and the response factor was calculated. Each concentration was analyzed in triplicate, and the mean values were calculated. A linear zerointercept relationship was established where the slope and correlation coefficient were 0.0355 and 1.00 , respectively. The percent recoveries ranged from $99 \%$ to $112 \%$, and the average response factor was $27.48 \pm 1.77$. 
Study of FTC Variables on DS Release from Voltaren (R1):

The FTC, USP Apparatus 4, was a Dissotest CE-6

equipped with a CY 7-50 piston pump (Sotax, Switzerland). A built-in filtration system with $0.7-\mu \mathrm{m}$ Whatman glass microfiber (GF/F and GF/D) and glass wool was used throughout the study. The temperature of the dissolution medium was kept at $37 \pm 0.5^{\circ} \mathrm{C}$. The dissolution medium used throughout the experiments was $\mathrm{pH} 6.8$ phosphate buffer that was filtered $(0.45 \mu \mathrm{m})$ and degassed. Fractions were collected every half-hour up to $4 \mathrm{~h}$, and DS concentrations were analyzed spectrophotometrically. The dissolution studies were carried out in triplicate. Two flow-through cells having internal diameters of $12 \mathrm{~mm}$ (small cell) and $22.6 \mathrm{~mm}$ (large cell) were used.

The FTC was operated without glass beads (turbulent flow, Figure $2 \mathrm{~A}$ ) or in the presence of glass beads, each 1-mm in diameter (laminar flow, Figure 3A), where the tablet was buried in the glass beads. The dissolution medium was pumped at flow rates of 8 and $16 \mathrm{~mL} / \mathrm{min}$.

The dissolution studies were performed with the tablet secured on a tablet holder (Figure $2 \mathrm{~B}$ ) and without a tablet holder (Figure 2A).

Tablets were positioned in three patterns as follows: (1) The tablet was buried in a bed of glass beads (Figure 3A). (2) The tablet was placed on a bed of glass beads filling the conical part of the cell (Figure 3B). (3) The tablet was placed on a bed of glass beads that filled the whole dissolution cell (Figure 3C). The effect of tablet position within the glass beads was studied using both the small and large dissolution cells.

\section{RESULTS AND DISCUSSION}

DS is the salt of a weak acid and is practically insoluble in acidic medium. In dissolution media with $\mathrm{pH}$ values greater than 1 unit below the $\mathrm{p} K_{a}$, DS is present mostly in its free acid form, which is less soluble than the salt form. Consequently, the solubility of DS in dissolution medium with $\mathrm{pH}<3$ is very low. As the $\mathrm{pH}$ increases, the solubility of DS increases due to the contribution from the ionized form until the highest solubility is reached in $\mathrm{pH} 8.0$ phosphate buffer solution (22). In most studies, the dissolution of DS is carried out in $\mathrm{pH} 6.8$ phosphate buffer according to USP XXIII (23).

The dissolution profiles obtained using the small and large cells are illustrated in Figure 4. For turbulent flow (Figure 4A), the cell size had almost no effect on the DS dissolution rate. The percent of DS released was $44 \%$ and $43 \%$ from the small and large cell, respectively.

For laminar flow, in which the tablet was buried in glass beads, there was a slight increase in the amount of DS released on applying the small cell (Figure 4B). Also, no difference was found when tablets were placed on the top of the glass beads, whether the glass beads filled the conical part of the cell (Figure 4C) or the cylindrical part of the cell (Figure 4D). These results could eliminate the step of weighing the glass beads before loading into the cell,

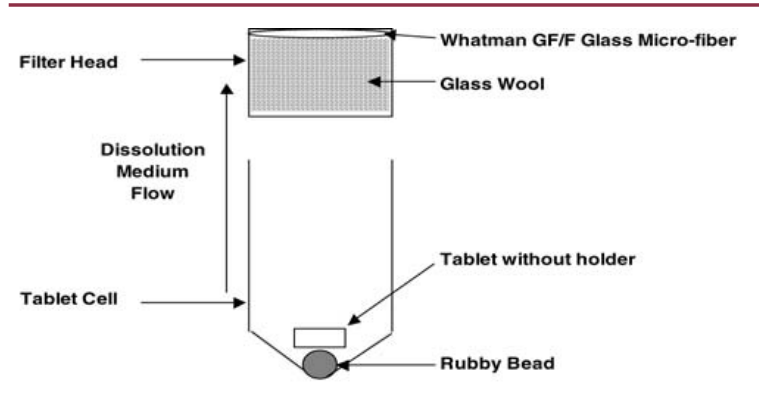

(A)

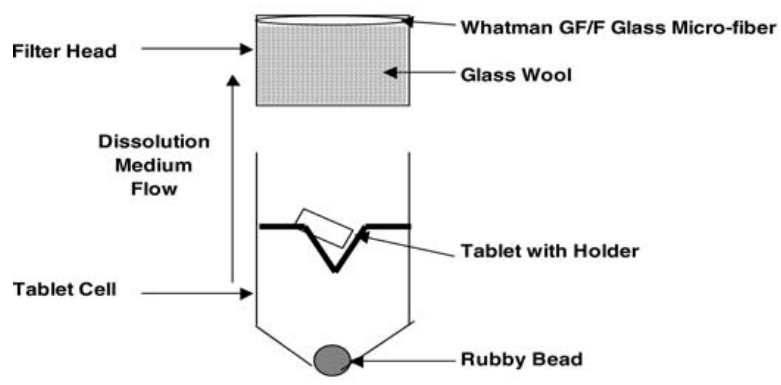

(B)

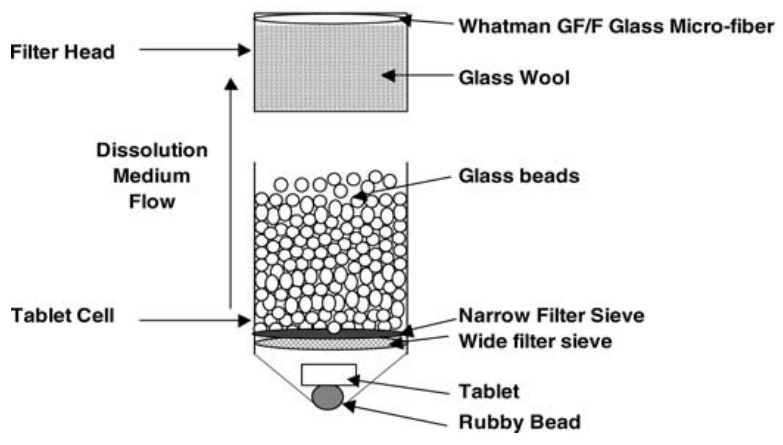

(C)

Figure 2. Schematic diagrams showing different positions of tablet in the turbulent flow of the FTC $(A)$ without a holder; $(B)$ with a holder; and $(C)$ in a defined volume of cell.

which in turn, could lead to a more simplified experimental design. On the other hand, in previous studies $(16,19)$, the dissolution rates of salicylic acid and prednisone tablets in the large cell were significantly lower than those in the small cell. Similarly, the dissolution rates of nifedipine from commercially available controlled-release tablets in the large cell were significantly lower than those in the small cell (24). Therefore, it could be concluded that the amount of DS released per unit time is constant and might not be affected by changes in the linear velocity of the medium. In the small cell, the fresh dissolution medium is recirculated faster, and the concentration of a given drug in the diffusion layer around the tablet is affected by the concentration gradient. This gives rise to more drug diffusion, which is expected to increase the amount of drug released. However, applying a small or large cell has no effect on the release rate of DS, which means that the saturation concentration of DS is rather high to be affected by the cell size. 


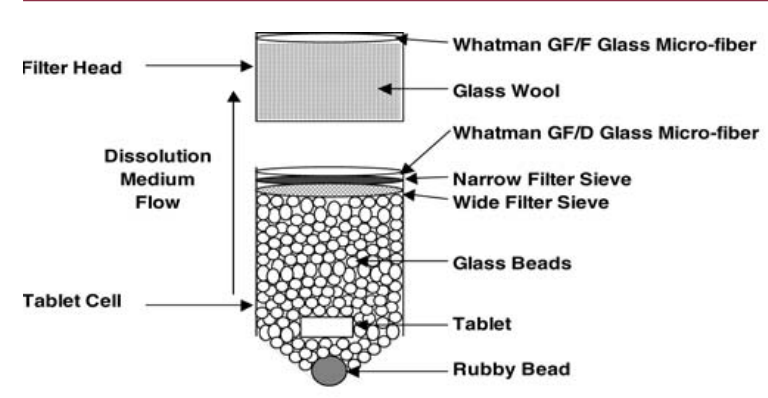

(A)

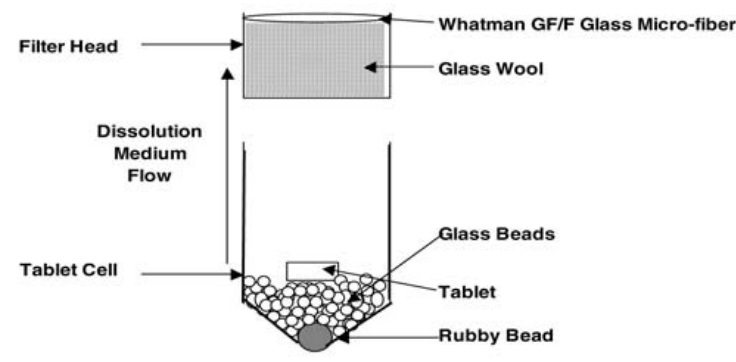

(B)

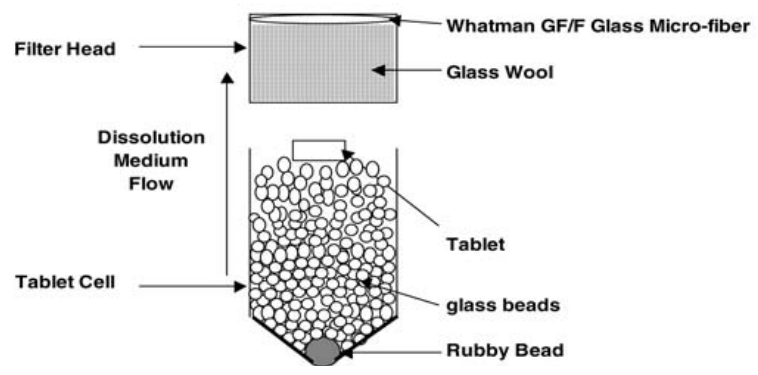

Figure 3. Schematic diagrams showing different positions of tablet within the glass beads bed. (A) Buried tablet; (B) free tablet position (glass beads fill conical part); (C) free tablet position (glass beads fill cylindrical part).

Figure $5 A, B$ shows the effect of turbulent and laminar flow on the amount of DS released (cf. schematic diagrams Figures $2 \mathrm{~A}$ and $3 \mathrm{~A}$ ). It was found that in both the large and the small dissolution cells, the amount of DS released increased remarkably on applying the turbulent flow conditions. In the small cell, the percent of DS released was $44 \%$ and $29 \%$ when the turbulent and laminar flow was applied, respectively. In addition, in the large cell, the percent of DS released was $43 \%$ and $22 \%$ for turbulent and laminar flow, respectively. The observed increase in the release rate of DS upon applying the turbulent flow might be explained by the free position of the tablet, which allows more hydrodynamic effect around the tablet. This causes rather heavy and turbulent agitation, which is enough to increase the release rate. On the other hand, the use of glass beads in the dissolution cell serves as an equalizer to maintain a laminar flow pattern, thus decreasing the agitation around the tablet. In contrast, Morihara et al. (20) studied the release of salicylic acid from USP calibrator tablets and reported that the release rate reached its highest value when the tablet was buried in the glass beads compared with resting the tablet on top the glass beads or leaving the tablet free in the cell with no glass beads (i.e., turbulent flow). This result does not agree with the present study, in which the release rate of DS reached its highest value in turbulent flow. Thus, for each drug or product, the optimum criteria and conditions of the dissolution design should be considered to discriminate between different products or the changing of excipients or manufacturing site of the product.

The effect of different flow rates is illustrated in Figure $6 A, B$, which shows that there was no difference in the release of DS for the two applied flow rates (8 and $16 \mathrm{~mL} / \mathrm{min}$ ). Upon using the large cell and the tablet placed on top of glass beads (Figure 6A), the percent of DS released was $44 \%$ and $43 \%$ with flow rates of $8 \mathrm{~mL} / \mathrm{min}$ and $16 \mathrm{~mL} / \mathrm{min}$, respectively. Similarly, when using the small cell and the tablet buried in the glass beads (Figure 6B), the percent DS released was $28 \%$ and $32 \%$ at 8 and $16 \mathrm{~mL} / \mathrm{min}$, respectively. These results indicate that increasing the flow rate from 8 to $16 \mathrm{~mL} / \mathrm{min}$ does not affect the amount of DS released, whether the tablet position was free or embedded, or on using either the small or the large cell. In another study (16), the dissolution rate of nondisintegrating salicylic acid tablets progressively increased with increasing flow rate in the small cell. Moreover, the statistical comparison indicated that at each flow rate, the dissolution rates in the large cells were significantly lower than those in the small cells. In a study of disintegrating prednisone tablets (19) with laminar flow (buried tablet), the release at $16 \mathrm{~mL} / \mathrm{min}$ was higher than at $8 \mathrm{~mL} / \mathrm{min}$, and the difference between the two flow rates was much higher upon using the large cell compared with the small cell. Because changing the flow rate from 8 to $16 \mathrm{~mL} / \mathrm{min}$ does not alter the release rate of DS, it is more convenient to adjust the flow rate to $8 \mathrm{~mL} / \mathrm{min}$. This will minimize the dissolution medium and chemicals needed to perform the dissolution tests.

Figure 7 compares the effect of different patterns of the turbulent flow (cf. schematic diagrams Figure $2 A, C$ ) on the release of DS. The percent of DS released was not affected by different patterns of turbulent flow in the FTC. The effect of placing the tablet either free in the cell with no glass beads (i.e., turbulent flow throughout the cell) or in a free position in the conical part of the cell with glass beads filling the cylindrical part (i.e., turbulent flow limited to the conical part of the cell) has not been reported. However, a personal communication (25) suggested the latter design to evaluate the release rate of DS from Voltaren Resinate $75 \mathrm{mg}$. This may be the best design for this specific product. In addition, the in vitro results may be critical in vivo because of the inability of the dissolution design to discriminate between specific products.

The effect of mounting the tablet in place using clips or a holder is presented in Figure 8. The results show that DS release was not affected by the presence or absence of a tablet holder. After $4 \mathrm{~h}$, the percent released was 
(A)

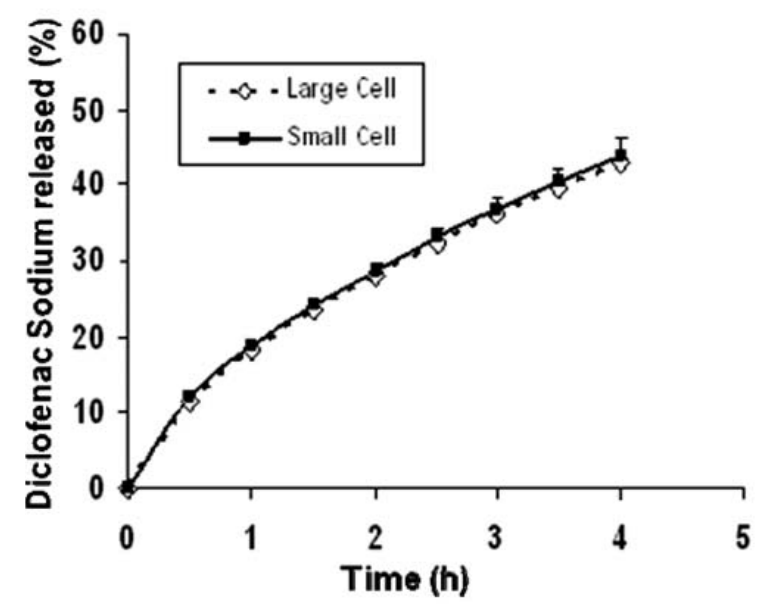

(B)

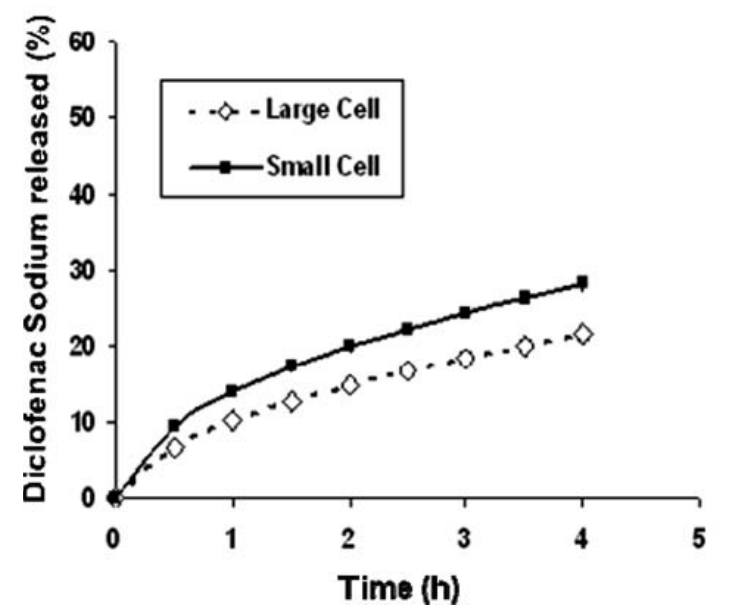

(C)

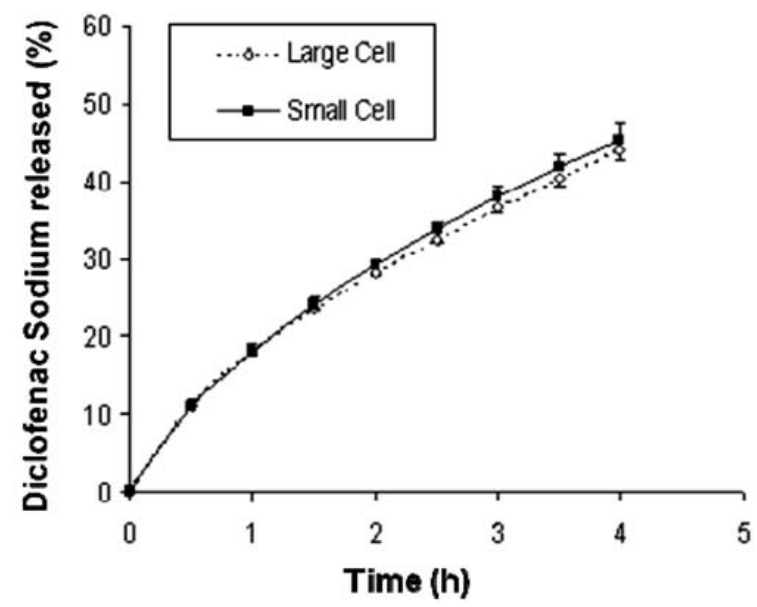

(D)

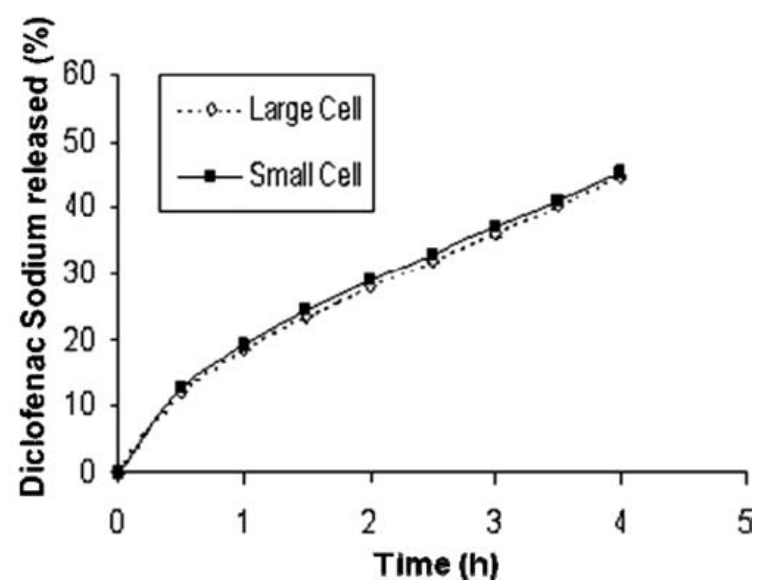

Figure 4. Effect of cell size. (A) Turbulent flow, free tablet; (B) laminar flow, buried tablet; (C) free tablet ( $g$ lass beads filled conical part); (D) free tablet ( $g l a s s$ beads filled cylindrical part).

about $43 \%$ for either position (i.e., free position or tablet mounted in place using a tablet holder). Again, in a previous study (19), it was reported that the release of nondisintegrating salicylic acid tablets using a tablet holder was different from the release without a holder, using both the small and large dissolution cells. The percent of salicylic acid released using the tablet holder was $65 \%$ versus $99 \%$ without the holder. While the present study differs from the above study, it agrees with another study (20) done on a disintegrating prednisone tablet, where no difference in release rate was obtained when the tablet was left free or placed on a holder.

The effect of the amount of glass beads loaded in the FTC and tablet position within the glass beads is demonstrated in Figure 9A,B. Diagrams of the different designs are found in Figure $3 \mathrm{~A}-\mathrm{C}$. Using the small and large cells, the release of DS was much lower when the tablet was buried in the glass beads than when the tablet was placed on top of the bed of glass beads in the two systems (i.e., filling the conical part of the cell or filling the whole cell with glass beads). In a study by Morihara et al. (20), the release of salicylic acid from USP calibrator tablets was the highest when the tablet was buried in the glass beads, followed by placement on top of the glass beads bed. In another study (18), different designs of powder loading within the glass beads and their impact on dissolution of a poorly soluble compound (PD 198306) were investigated. The results showed that the lowest release rate was obtained when the drug powder was embedded in a glass-bead bed, while homogeneous mixing of the drug with glass beads was the best method of drug loading into the cell. 
(A)

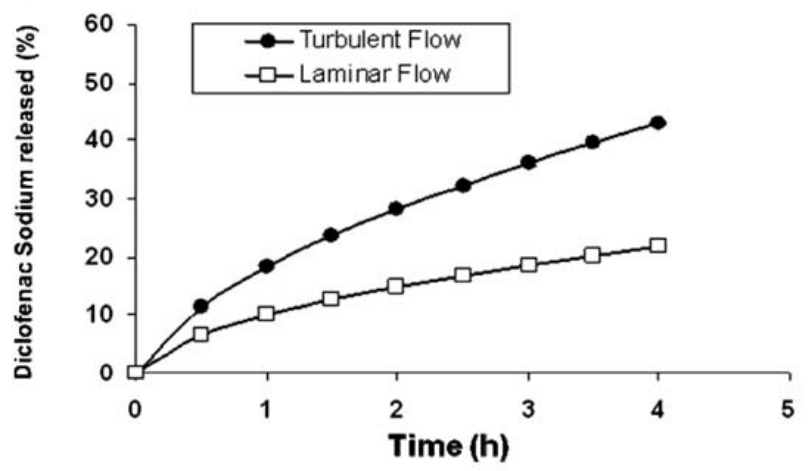

(B)

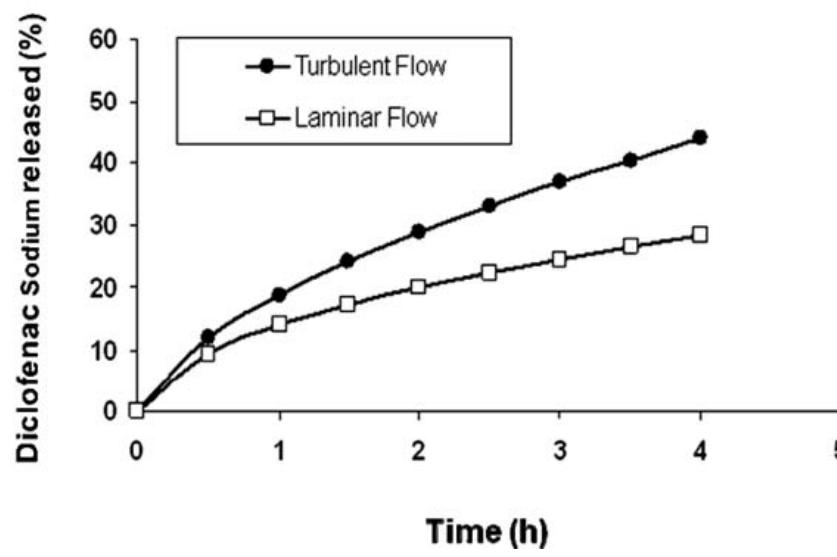

Figure 5. Effect of the type of flow of the dissolution medium, (A) large cell; (B) small cell.

Based on the above results, the FTC design of a large dissolution cell, free tablet position, turbulent flow condition, and $8 \mathrm{~mL} / \mathrm{min}$ flow rate of dissolution medium was selected to carry out comparative in vitro release studies of five different commercially available SR products, each containing $100 \mathrm{mg}$ DS. This design was selected because it achieves the optimum conditions for DS release rate. $\mathrm{R} 1$ and $\mathrm{R} 2$ are the reference products of DS available in the Egyptian and European markets, respectively, while G1, G2, and G3 are the generic products available in the Egyptian market. The dissolution studies were carried out using the open system of the FTC, with cell design shown in Figure 2A. The sequence of dissolution medium used was $0.1 \mathrm{~N} \mathrm{HCl}$ of $\mathrm{pH} 1.2$ for the first $2 \mathrm{~h}$, followed by $\mathrm{pH} 6.8$ phosphate buffer for $6 \mathrm{~h} \mathrm{(23).}$

Figure 10 shows distinct differences in the percent of DS released from the commercial marketed products. The generic products exhibited the highest release rate $(90 \%$, $87 \%$, and $86 \%$ for $\mathrm{G} 1, \mathrm{G} 2$ and $\mathrm{G} 3$, respectively). On the other hand, the reference products exhibited lower release rates, where $55 \%$ and $39 \%$ of DS were released after $8 \mathrm{~h}$ from $\mathrm{R} 1$ and $\mathrm{R} 2$, respectively.
(A)

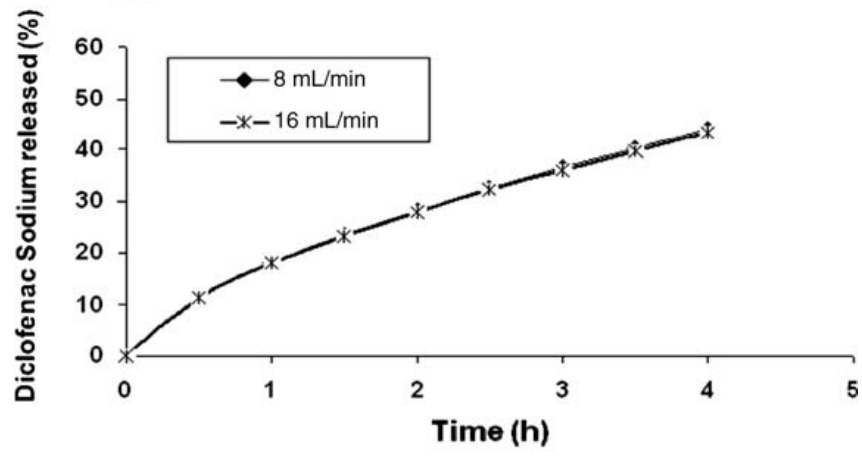

(B)

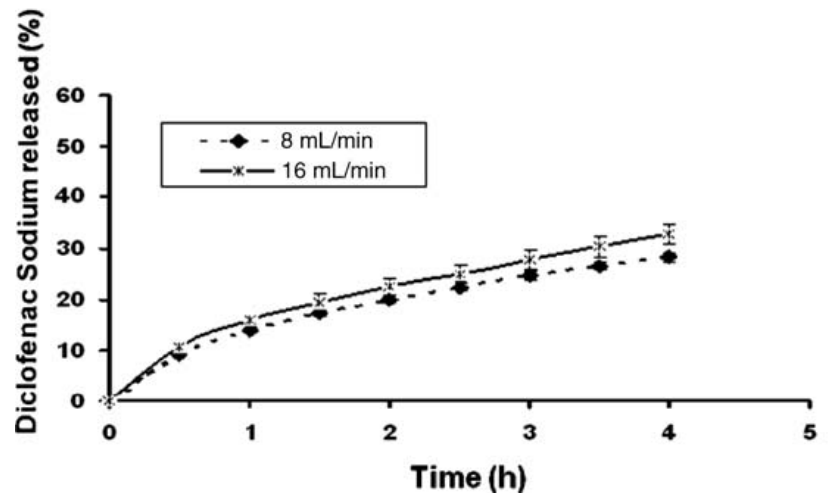

Figure 6. Effect of flow rate on the dissolution medium: (A) large cell (free tablet on top of glass beads); (B) small cell (tablet buried within glass beads bed).

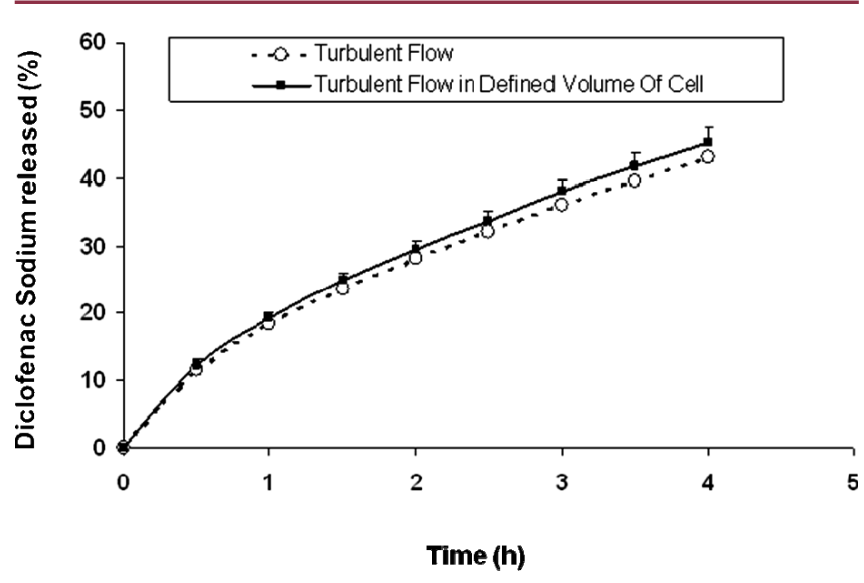

Figure 7. Effect of different patterns on turbulent flow.

Therefore, a more specified test for comparing the different products was applied. Moore and Flanner (26) proposed a simple model-independent approach using mathematical indices to define the difference factor and similarity factor for comparing dissolution profiles. This approach has also been recommended for dissolution 


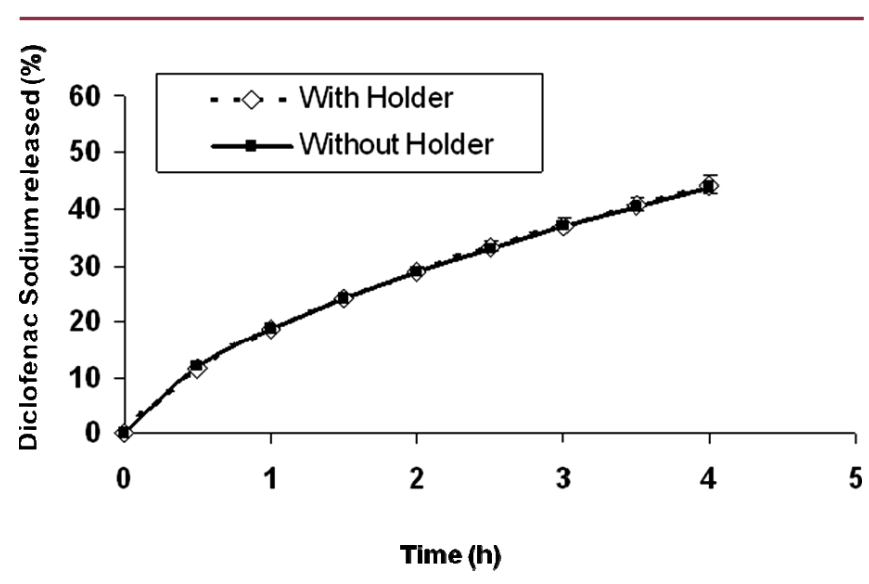

Figure 8. Effect of the tablet holder.

$$
\text { (A) }
$$

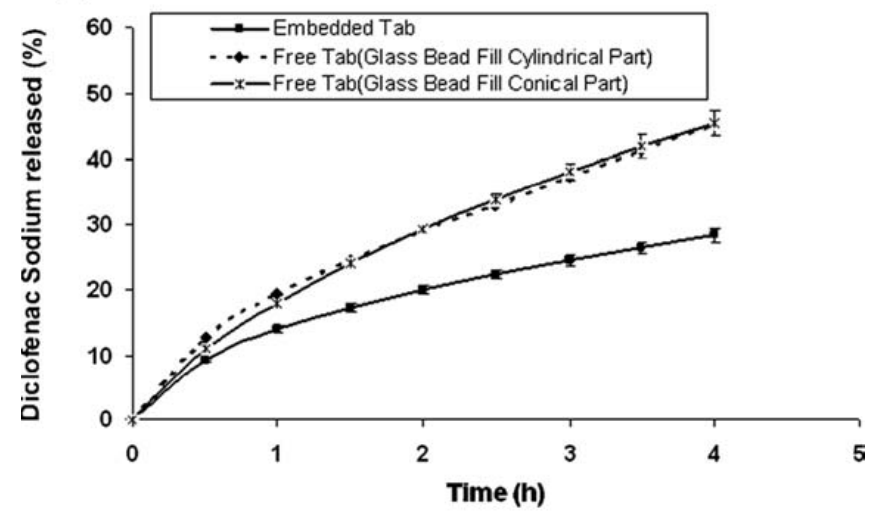

(B)

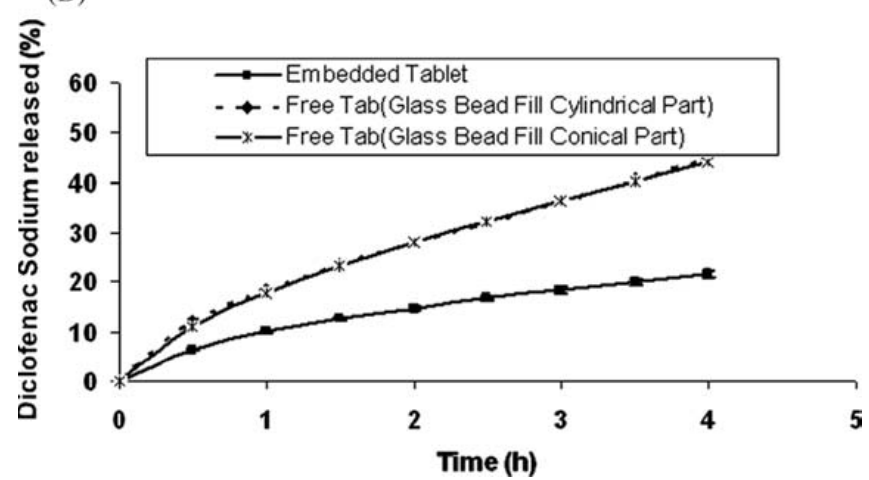

Figure 9. Effect of different tablet positions within the glass beads: (A) large cell; (B) small cell.

profile comparison in an FDA Guidance for Industry (27). The similarity factor $f_{2}$ is simple and can be easily adopted by the industry.

The similarity factor $f_{2}$ is defined by FDA (28) as

$$
f_{2}=50 \times \log \left\{\left[1+\left(\frac{1}{n}\right) \sum_{t=1}^{n}\left(R_{t}-T_{t}\right)^{2}\right]^{-0.5} \times 100\right\}
$$

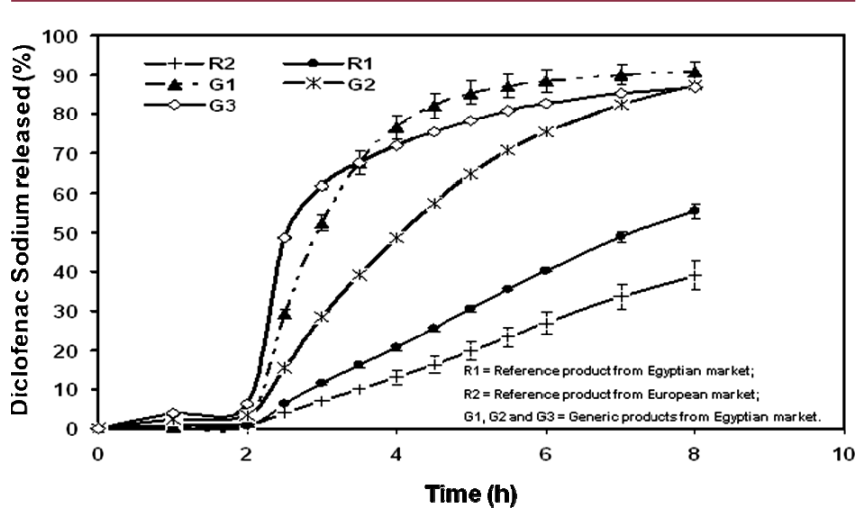

Figure 10. Percent release of DS from SR marketed products (100 mg DS/ Product) using the FTC ( 2 h at $p H 1.2$ followed by $6 h$ at $p H 6.8$ ).

where $n$ is the number of time points, and $R_{t}$ and $T_{t}$ are the cumulative percentage release at the selected $n$ time point of the reference and the test products, respectively.

When two profiles are identical, $f_{2}$ is 100 . An average difference of $10 \%$ at all measured time points results in an $f_{2}$ value of 50. FDA has set a public standard of an $f_{2}$ value of 50-100 to indicate similarity between two dissolution profiles (26).

Dissolution profiles for the reference product R2 were compared with those of product R1 as well as the three generic products (G1, G2, and $\mathrm{G} 3$ ) by calculation of similarity factor $f_{2}$, and the values were as follows: 50,27 , 15 , and 29 for R1, G1, G2, and G3, respectively. These values show that the reference product $\mathrm{R} 1$, available in the Egyptian market, had a similar dissolution profile to the reference product R2, available in the European market, while the generic products exhibited dissimilar dissolution profiles.

These results raise questions about the in vivo performance of the products and hence the serious possibility of bioinequivalence.

The FDA provides guidelines for dissolution tests for oral modified-release dosage forms (29), but also realizes the need for individualizing the method on a case-by-case basis, leaving the justification of a given methodology to the scientists. Therefore, scientists are requested to design an appropriate test based on the objectives (e.g., quality control, in vitro-in vivo correlations, showing bioequivalency).

\section{CONCLUSIONS}

The FTC was developed to answer some deficiencies perceived in other compendial techniques. To successfully employ the FTC technique for testing the release of DS from different SR products, it is critical that the test preparation should be maintained in defined conditions during testing. Based on the results of the current study, it can be concluded that the release of DS from SR 
preparations is affected by the type of flow and the position of the tablet within the glass beads bed, and not affected by the cell size, flow-rate variations, or amount of glass beads present in the cell. Most of the results of this study do not totally agree with other studies using different drugs or preparations. Therefore, the FTC technique still deserves further investigation on a case-by-case basis. To successfully employ the FTC for testing a drug product, knowledge of the optimum conditions that could discriminate between products is a prerequisite for performing the test and for developing an in vivo-in vitro correlation.

\section{REFERENCES}

1. Banakar, U.V.; Block, L. H. Beyond bioavailability testing. Pharm. Technol. 1983, 7 (9), 107-117.

2. Gohel, M. C.; Panchal, M. K. Refinement of Lower Acceptance Value of the Similarity Factor $f_{2}$ in Comparison of Dissolution Profiles. Dissolution Technol. 2002, 9 (1) 18-22.

3. Banaker, U.V.Pharmaceutical Dissolution Testing, Marcel Dekker, Inc.: New York, 1992.

4. Shah, A. C.; Ochs, J. F. Design and evaluation of a rotating filter-stationary basket in vitro dissolution test apparatus. II. Continuous fluid flow system. J. Pharm. Sci. 1974, 63 (1), 110-113.

5. Kellaway, I. W.; Marriott, C. J. Pharmaceutical applications of solid dispersion systems. J.Pharm. Sci. 1975, 64, 1162-1169.

6. Lin, S. L.; Menig, J.; Swartz, C. J. Comparative evaluation of various dissolution apparatus for capsule dosage forms. J. Pharm. Sci. 1970, 59 (7), 989-994.

7. Khan, K. A.; Rhodes, C.T.The production of tablets by direct compression. Can. J. Pharm. Sci. 1973, 8, 1-5.

8. Cox, D. C.; Furman, W. B. Systematic error associated with apparatus 2 of the USP dissolution test I: effects of physical alignment of the dissolution apparatus. J.Pharm. Sci. 1982, 71 (4), 451-452.

9. Moore, T.W.; Hamilton, J. F.; Kerner, C. M. Dissolution testing: limitations of the USP prednisone and salicylic acid calibrator tablets. Pharm. Forum 1995, 21, 1387-1396.

10. Qureshi, S. A.; McGilveray, I. J.Typical variability in drug dissolution testing: study with USP and FDA calibrator tablets and a marketed drug (glibenclamide) product. Eur. J.Pharm. Sci. 1999, 7, 249-258.

11. Qureshi, S.A., Shabnam, J., 2001. Cause of high variability in drug dissolution testing and its impact on setting tolerence. Eur. J. Pharm. Sci., 12, 271-276.

12. Zhang, G. H.; Vadino, W. A.; Yang, T.T.; Cho, W. P.; Chaudry, I. A. Evaluation of the flow-through cell dissolution apparatus: effects of flow rate, glass beads and tablet position on drug release from different type of tablets. Drug Dev. Ind. Pharm. 1994, 20 (13), 2063-2078.

13. Nicklasson, M.; Wennergren, B.; Lindberg, J.; Persson, C.; Ahlgren, R.; Palm, B.; Pettersson, A.; Wenngren, L. A collaborative in vitro dissolution study using the flowthrough method. Int. J. Pharm. 1987, 37, 195-202.

14. Wennergren, B.; Lindberg, J.; Nicklasson, M.; Nilsson, G.; Nyberg, G.; Ahlgren, R.; Persson, C.; Palm, B. A collaprative in vitro dissolution study: comparing the flow-through method with the USP paddle method using USP prednisone calibrator tablets. Int. J. Pharm. 1989, 53, 35-41.

15. Saleh, S. I.; Khider, S. H.; Aiache, J. M.; Beyssac, E.; Camacho, R. Comparative dissolution profiles of five internationally-available sustained-release diclofenac sodium dosage forms. S.T.P. Pharma Sci. 1992, 2 (3), 242-246.

16. Cammarn, S. R.; Sakr, A. Predicting dissolution via hydrodynamics: salicylic acid tablets in flow through cell dissolution. Int. J. Pharm. 2000, 201, 199-209.

17. Emara, L. H.; El-Menshawi, B. S.; Estefan, M. Y. In vitro-in vivo correlation and comparative bioavailability of vincamine in prolonged-release preparations. Drug Dev. Ind. Pharm. 2000, 26 (3), 243-251.

18. Battachar, S. N.; Welsey, J. A.; Fioritto, A.; Martin, P. J.; Babu, S. R.. Dissolution testing of a poorly soluble compound using the flow-through cell dissolution apparatus. Int. J. Pharm. 2002, 236, 135-143.

19. Bielen, N. Performance of USP calibrator tablets in flow-through cell apparatus. Int. J. Pharm. 2002, 233, 123-129.

20. Morihara, M.; Aoyagi, N.; Kaniwa, N.; Katori, N.; Kojim, S. Hydrodynamic flows around tablets in different pharmacopeial dissolution tests. Drug Dev. Ind. Pharm. 2002, 28 (6), 655-662.

21. Adeyeeye, C. M.; Li, P. K. Diclofenac Sodium. In Analytical Profiles of Drug Substances and Excipients; Florey, K., Ed.; Academic Press: New Jersey, 1990; Vol. 19, pp 123-144.

22. Kincl, M.; Vercer, F.; Veber, M. Characterization of factors affecting the release of low-solubility drug from prolonged release tablets. Anal. Chim. Acta 2004, 502, 107-113.

23. United States Pharmacopeia and National Formulary USP 23-NF 18; The United States Pharmacopeial Convention, Inc.: Rockville, MD, 1995.

24. Badr, R. M. Improvement of Nifidepine Bioavailability in Oral Drug Delivery Systems. Ph.D. Thesis, Cairo University, Egypt, 2006.

25. Emara, L. H. Novartis Pharma, Egypt. Personal communication, 1996.

26. Moore, J.W.; Flanner, H. H. Mathematical comparison of dissolution profiles. Pharm. Technol. 1996, 20 (6), 64-67.

27. Dissolution Testing of Immediate Release Solid Oral Dosage Forms; Guidance for Industry; U.S. Department of Health and Human Services, Food and Drug Administration, Center for Drug Evaluation and Research (CDER), U.S. Government Printing 
Office:Washington, DC, 1997. http://www.fda.gov/ cder/guidance/1713bp1.pdf (accessed Mar 19, 2009).

28. Shah, V. P.; Tsong, Y.; Sathe, P.; Liu, J. P. In Vitro Dissolution Profile Comparison-Statistics and Analysis of the Similarity Factor, $f_{2}$. Pharm. Res. 1998, 15 (6), 889-896.

29. SUPAC-MR: Modified-Release Solid Oral Dosage Forms: Scale-Up and Postapproval Changes: Chemistry,
Manufacturing, and Controls; In Vitro Dissolution Testing and In Vivo Bioequivalence Documentation; Guidance for Industry; U.S. Department of Health and Human Services, Food and Drug Administration, Center for Drug Evaluation and Research (CDER), U.S. Government Printing Office:Washington, DC, September 1997. http://www.fda.gov/cder/guidance/ 1214fnl.pdf (accessed Mar 19, 2009). 